\title{
Layered implantation of myoblast sheets attenuates adverse cardiac remodeling of the infarcted heart
}

\author{
Naosumi Sekiya, MD, ${ }^{\text {a }}$ Goro Matsumiya, $\mathrm{MD}, \mathrm{PhD},{ }^{\text {a }}$ Shigeru Miyagawa, MD, $\mathrm{PhD},{ }^{\text {a }}$ Atsuhiro Saito, $\mathrm{PhD},{ }^{\mathrm{a}}$ \\ Tatsuya Shimizu, MD, PhD, ${ }^{\mathrm{b}}$ Teruo Okano, $\mathrm{PhD},{ }^{\mathrm{b}}$ Naomasa Kawaguchi, $\mathrm{PhD},{ }^{\mathrm{c}}$ \\ Nariaki Matsuura, $\mathrm{MD}, \mathrm{PhD},{ }^{\mathrm{c}}$ and Yoshiki Sawa, $\mathrm{MD}, \mathrm{PhD}^{\mathrm{a}}$
}

\begin{abstract}
Objective: We previously showed that autologous myoblast sheets constructed with tissue-engineering techniques improved the function of the impaired heart. In this study, we evaluated the effects of layered myoblast sheets to clarify whether increasing the number of sheets provides improvement of cardiac function.
\end{abstract}

\begin{abstract}
Methods: Myoblast sheets were constructed in dishes that release confluent cells from the dish surface via temperature reduction. Sixty infarcted Lewis rats underwent implantation of myoblast sheets on the infarcted area. There were 4 groups ( $\mathrm{n}=15$ in each group): S1: one layer, S3: three layers, S5: five layers, and a sham group. We examined cardiac function by echocardiography and catheterization, mRNA expression by real time reversetranscriptase polymerase chain reaction, and histology.

Results: The ejection fraction and end-systolic pressure-volume relationship in the S5 and S3 groups were significantly improved. End-diastolic area was significantly reduced in the S5 group. The mRNAs for hepatocyte growth factor, vascular endothelial growth factor, and stromal cell-derived factor-1 were all upregulated in dose-dependent fashion. On histologic examination, fibrosis was most decreased in S5, and vascular density was increased. Cellular hypertrophy was attenuated in both the S5 and S3 groups. Elastic fibers were massively up-regulated in the infarction and implanted sheets in the S5 and S3 groups, with expression of the elastin gene.
\end{abstract}

Conclusions: Implantation of three- and five-layered myoblast sheets yields favorable results, with better improvement of cardiac function, induction of angiogenesis, more elastic fibers, and less fibrosis. Thus, layered myoblast sheets, in optimal numbers, may attenuate adverse cardiac remodeling of the infarcted heart.

Myocardial regeneration therapy has been widely performed for myocardial infarction (MI). Cell transplantation using skeletal myoblasts has commonly been undertaken in animal models as well as in clinical trials. ${ }^{1,2}$ Most myoblast transplantation studies for cardiac failure have supported the feasibility and safety of this method. ${ }^{3-6}$ In these studies, the method of cell transplantation was direct myocardial injection with a fine needle. However, needle injection has some disadvantages, including loss of transplanted cells by leakage, poor survival of grafted cells, myocardial damage resulting from injury by the needle and subsequent acute inflammation, ${ }^{7,8}$ and the potential to cause a lethal arrhythmia. ${ }^{6}$ To overcome these disadvantages, we investigated the efficacy of a novel

\footnotetext{
From the Department of Cardiovascular Surgery, ${ }^{\text {a }}$ Osaka University Graduate School of Medicine, Osaka; the Institute of Advanced Biomedical Engineering and Science, ${ }^{\mathrm{b}}$ Tokyo Women's Medical University, Tokyo; and the Department of Molecular Pathology, ${ }^{\mathrm{c}}$ Osaka University Graduate School of Allied Health Science, Osaka, Japan.

This work was supported by the New Energy and Industrial Technology Development Organization in Japan.

Read at the Eighty-eighth Annual Meeting of The American Association for Thoracic Surgery, San Diego, Calif, May 10-14, 2008.

Received for publication May 15, 2008; revisions received Jan 7, 2009; accepted for publication Feb 2, 2009

Address for reprints: Yoshiki Sawa, MD, PhD, 2-2 Yamada-oka, Suita, Osaka, 5650871, Japan (E-mail: sawa@surg1.med.osaka-u.ac.jp).

J Thorac Cardiovasc Surg 2009;138:985-93

$0022-5223 / \$ 36.00$

Copyright $(c) 2009$ by The American Association for Thoracic Surgery

doi:10.1016/j.jtcvs.2009.02.004
}

transplantation technique using cell sheets grown in temperature-responsive dishes. ${ }^{9}$ Myoblast sheets, without scaffolding, were implanted to treat cardiac impairment in small and large experimental animal models, and greater improvement of cardiac function was observed as compared with that obtained by needle injection and control groups. ${ }^{10-13}$

However, the method of cell delivery in these studies had several limitations, including the implantation method (implanting two-layered myoblast sheets with collagen film to keep the sheets on the heart) and delivery of an optimal number of cells. It has been unclear whether delivery of more cells will be more effective in inducing cardiac regeneration. It has also not been clearly determined whether increasing the number of layers would yield better results. Shimizu and coworkers ${ }^{14}$ reported that transplanted three-layered sheets of cardiomyocytes could be vascularized in subcutaneous tissue without necrosis, but that sheets with four or five layers have areas with disorganized vasculature and primary ischemia.

Our previous reports ${ }^{10,11}$ showed that implantation of two-layered, autologous myoblast sheets improved cardiac function and prevented remodeling of the infarcted heart. In this study, we tested whether increasing the number of layered myoblast sheets would enhance functional recovery and attenuate adverse cardiac remodeling of the infarcted heart to estimate the optimal number of myoblast sheet layers for regeneration of host heart. 


$$
\begin{aligned}
& \text { Abbreviations and Acronyms } \\
& \begin{aligned}
\text { HGF } & =\text { hepatocyte growth factor } \\
\text { LV } & =\text { left ventricular } \\
\text { LVEF } & =\text { left ventricular ejection fraction } \\
\text { MI } & =\text { myocardial infarction } \\
\text { RT-PCR }= & \text { reverse-transcription polymerase } \\
& \text { chain reaction } \\
\text { SDF-1 } & \text { stromal-derived factor } 1 \\
\text { VEGF } & =\text { vascular endothelial growth factor }
\end{aligned}
\end{aligned}
$$

\section{MATERIAL AND METHODS Isolation of Myoblasts and Construction of Myoblast Sheets}

Myoblasts were isolated from the skeletal muscle of the anterior tibialis from 3-week-old male Lewis rats. The rats were humanely killed, and their skeletal muscles were excised and washed with Hanks balanced salt solution (Gibco, Grand Island, NY) containing $1 \times$ penicillin-streptomycin-amphotericin B (PSA; Gibco). After the removal of as much fibrous tissue, tendons, and fat tissue as possible, the muscles were minced and enzymatically dissociated with collagenase type II (Gibco) $(5 \mathrm{mg} / \mathrm{mL})$ and trypsinethylenediaminetetraacetic acid (Gibco) for 30 minutes. The cells were collected by centrifugation ( 5 minutes at $280 \mathrm{~g}$ ), and the enzyme reaction was arrested by adding $20 \%$ fetal bovine serum (ICN Biomedicals, Aurora, Ohio), after which the cells were spun again. The supernatant was discarded and the cells were resuspended in culture medium composed of Dulbecco modified Eagle solution (Gibco) with $20 \%$ fetal bovine serum and $1 \%$ penicillin-streptomycin-amphotericin B. The initial plating was performed in noncoated 150-mm dishes (Iwaki, Tokyo, Japan) for 4 hours. Secondary plating was performed in noncoated dishes for 20 hours. After being pre-plated twice, the nonadherent cells were placed in collagen-coated 150-mm dishes (Iwaki) and incubated for 3 days, after which cell passaging was performed into five collagen-coated dishes. When the cells became approximately $70 \%$ confluent after 7 days' cultivation, they were dissociated from the dishes with trypsin-ethylenediaminetetraacetic acid and reincubated on 35-mm temperature-responsive culture dishes (UpCell; Cellseed, Tokyo, Japan) at $37^{\circ} \mathrm{C}$, with cell number adjusted to $3.0 \times 10^{6}$ per dish. More than $70 \%$ of these cells were actin-positive and $40 \%$ to $50 \%$ were desmin-positive (Figure 1, $A$ to $D$ ). After 24 hours, the dishes were incubated at $20^{\circ} \mathrm{C}$ for 30 minutes. During that time, the myoblast sheets detached spontaneously to generate free-floating, monolayer cell sheets. After detachment, the area of the sheets decreased to $1.00 \pm 0.05$ $\mathrm{cm}^{2}$, whereas the thickness increased to $100 \pm 10.0 \mu \mathrm{m}$ (Figure 1,E).

\section{Animals and Surgical Procedures}

Eight-week old male Lewis rats were used (220-250 g; Seac Yoshitomi Ltd, Fukuoka, Japan). All experimental procedures and protocols used in this investigation were reviewed and approved by the institutional animal care and use committee and are in accordance with the National Institutes of Health Guide for the Care and Use of Laboratory Animals (NIH Publication No. 85-23, revised 1996). The rats were anesthetized with ketamine $(90 \mathrm{mg} / \mathrm{kg}$ ) and xylazine $(10 \mathrm{mg} / \mathrm{kg})$, and MI was induced by ligation of the left anterior descending coronary artery under mechanical ventilation, as previously described. ${ }^{15}$ Two weeks after the ligation, baseline cardiac functions were measured, and the infarcted rats underwent implantation of myoblast sheets via rethoracotomy. The rats were randomly divided into 4 treatment groups: (1) S1 group (one-sheet implantation); (2) S3 group (three-sheet implantation; (3) S5 group (five-sheet implantation); and a sham group (sham surgery alone). The myoblast sheets were implanted directly over the scar area without sutures. After detachment from the temperature-responsive dish, each sheet was picked up individually and applied to the surface of the heart. So that the sheet could be spread, the folded areas were gently stroked with wet, round tip forceps. After 3 to 5 minutes, subsequent sheets were applied by the same technique. After treatment, the pericardium was overwrapped by suturing with 8-0 Prolene polypropylene suture (Ethicon, Inc, Somerville, NJ) to prevent sheets from adhering to the chest wall.

\section{Assessment of Cardiac Function}

Left ventricular (LV) function of the treated rats was monitored by echocardiography 4 and 8 weeks after myoblast sheet implantation and compared with results before implantation (baseline). Cardiac ultrasonography was performed with a SONOS 5500 sonograph (Agilent Technologies, Palo Alto, Calif) using a $12-\mathrm{MHz}$ annular array transducer under anesthesia with diethyl ether. The hearts were imaged in short-axis 2-dimensional views at the level of the papillary muscles, and LV end-systolic area, LV end-diastolic area, and the LV dimensions at end-systole and end-diastole (LVDs, LVDd) were determined. Fractional shortening was determined as ([LVDd - LVDs]/LVDd) $\times$ 100. Ejection fraction (EF) was calculated by the Pombo method, as $\mathrm{EF}(\%)=\left(\left[\mathrm{LVDd}^{3}-\mathrm{LVDs}^{3}\right] / \mathrm{LVDd}^{3}\right) \times 100$.

Eight weeks after implantation, the rats were anesthetized and placed in a supine position on a controlled heating pad, and core temperature, measured via a rectal probe, was maintained at $37^{\circ} \mathrm{C} \pm 1^{\circ} \mathrm{C}$. A MicroTip catheter transducer (SPR-671; Millar Instruments, Inc, Houston, Tex) and conductance (Unique Medical Co, Tokyo, Japan) catheters were placed longitudinally in the left ventricle from the apex. We connected the catheters to an Integral 3 signal conditioner-processor (Unique Medical Co, Tokyo, Japan). LV pressure and volume and the electrocardiogram were displayed and digitized on a personal computer. LV pressure-volume relations were measured by transiently compressing the inferior vena cava. Data were recorded as a series of pressure-volume loops (about 20 loops). The pressure-volume loop data were analyzed with Integral 3 software (Unique Medical Co). ${ }^{16}$

\section{Histologic Examination}

LV myocardial specimens were obtained 4 weeks after sheet implantation. Each specimen was fixed with $10 \%$ buffered formalin and embedded in paraffin. Hematoxylin and eosin and Masson's elastica staining were performed. Picrosirius red staining to detect myocardial fibrosis and periodic acid-Schiff staining for cardiomyocyte hypertrophy were performed for specific treatment groups, as described. ${ }^{17}$ Anterior wall thickness was measured in at least 3 hematoxylin and eosin-stained sections of the middle portion of the left ventricle of each heart. To label vascular endothelial cells, so that blood vessels could be counted, we performed immunohistochemical staining for factor VIII-related antigen according to a modified protocol. We used EPOS-conjugated antibody to factor VIII-related antigen coupled with HRP (Dako EPOS Anti-human von Willebrand Factor/HRP; Dako, Carpenteria, Calif) as primary antibody. The stained vascular endothelial cells were counted under a light microscope. Results were expressed as the number of blood vessels per square millimeter. Quantitative morphorometric analysis for each sample was performed with MacScope software (Mitani Corporation, Tokyo, Japan). Myocardial fibrosis was expressed as percent fibrosis, the fraction of red-stained area in total myocardium, with results obtained from 10 fields per section per animal. To determine myocyte cell size, we randomly selected 10 fields from each ventricle and measured 5 randomly chosen myocytes per field.

\section{Measurement of Growth Factors and Elastin Gene Expression After Implantation}

Infarcted and noninfarcted LV myocardium from the rats having a ligated left anterior descending coronary artery was removed 4 weeks 

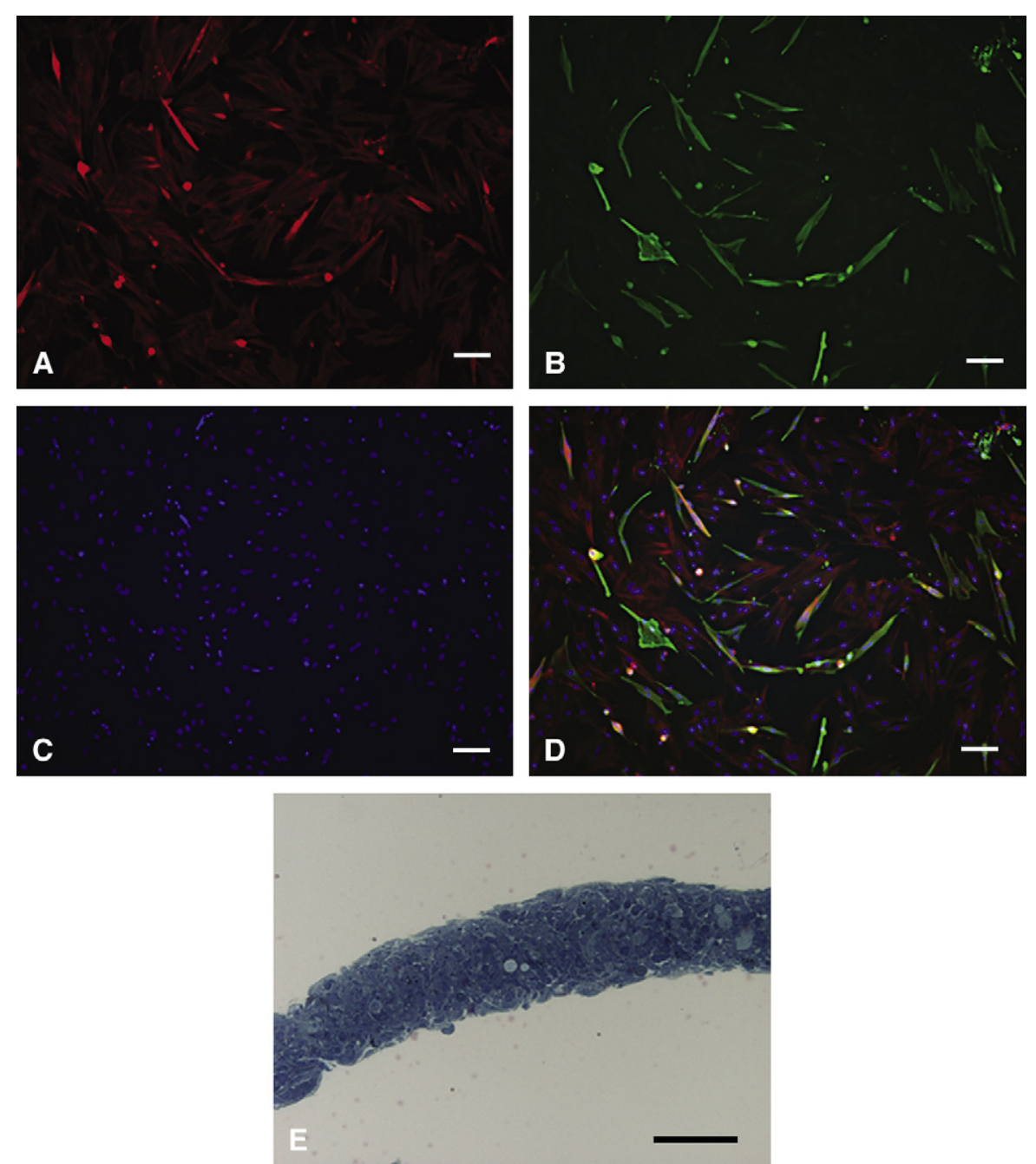

FIGURE 1. Cultured myoblasts and cross section of a sheet. Almost all cultured cells were actin-positive (A), and roughly $40 \%$ to $50 \%$ of them were desmin-positive muscle lineage cells (B). DAPI (4,6-diamino-2-phenylindole) staining of nuclei (C), and merged image (D) (A-D; magnification $\times 10$, $b a r=100 \mu \mathrm{m})$. Toluidine blue staining of cross section of sheet-constructed cells (E) $($ bar $=100 \mu \mathrm{m})$.

after implantation and immediately stored in RNAlater solution (Qiagen, Hilden, Germany) until use ( $\mathrm{n}=10$ for each of the 4 groups, S1, S3, S5, and sham). Total RNA was extracted with the RNeasy mini kit (Qiagen), and relative levels of mRNA transcripts were measured by the real-time quantitative reverse-transcriptase polymerase chain reaction (RT-PCR) technique using the ABI PRISM 7700 Sequence Detection System (Applied biosystems, Carlsbad, Calif). ${ }^{18}$ The average copy number of gene transcripts in each sample was normalized to that for glyceraldehyde-3-phosphate dehydrogenase, and fold induction of each gene was calculated by the formula: Fold induction $=$ Normalized value in a sample after MI/Mean of the normalized values for 15 reference myocardial samples.

\section{Data Analyses}

All values are the mean \pm standard error of the mean. To assess the significance of differences between individual groups, we performed statistical evaluations with multiple analyses of variance. Differences in cardiac function data obtained by echocardiography were assessed by 2-way repeatedmeasures analysis of variance. If a significant $F$ ratio was obtained, further analysis was carried out with a post hoc test.

\section{RESULTS}

\section{Layered Myoblast Sheet Implantation Improved} Cardiac Performance

Echocardiography revealed significant improvement of LV ejection fraction (LVEF) and percentage fractional shortening in the S3 and S5 groups compared with the S1 and sham groups 4 and 8 weeks after implantation. The LVEF 4 weeks after implantation in the S5 group was significantly improved compared with that in the S3 group $(P<$ .05 ) (Figure 2, $A$ and $B$ ). Enlargement of LV end-diastolic area was significantly attenuated in the S5 group compared with the sham and S1 groups at 4 weeks and differed significantly from the sham group 8 weeks after implantation (Figure $2, C$ ). The end-systolic pressure-volume relationship was significantly improved in both the S3 and S5 groups compared with the $\mathrm{S} 1$ and sham groups 8 weeks after implantation (Figure 2,D). Thus, implantation of sheets of at 

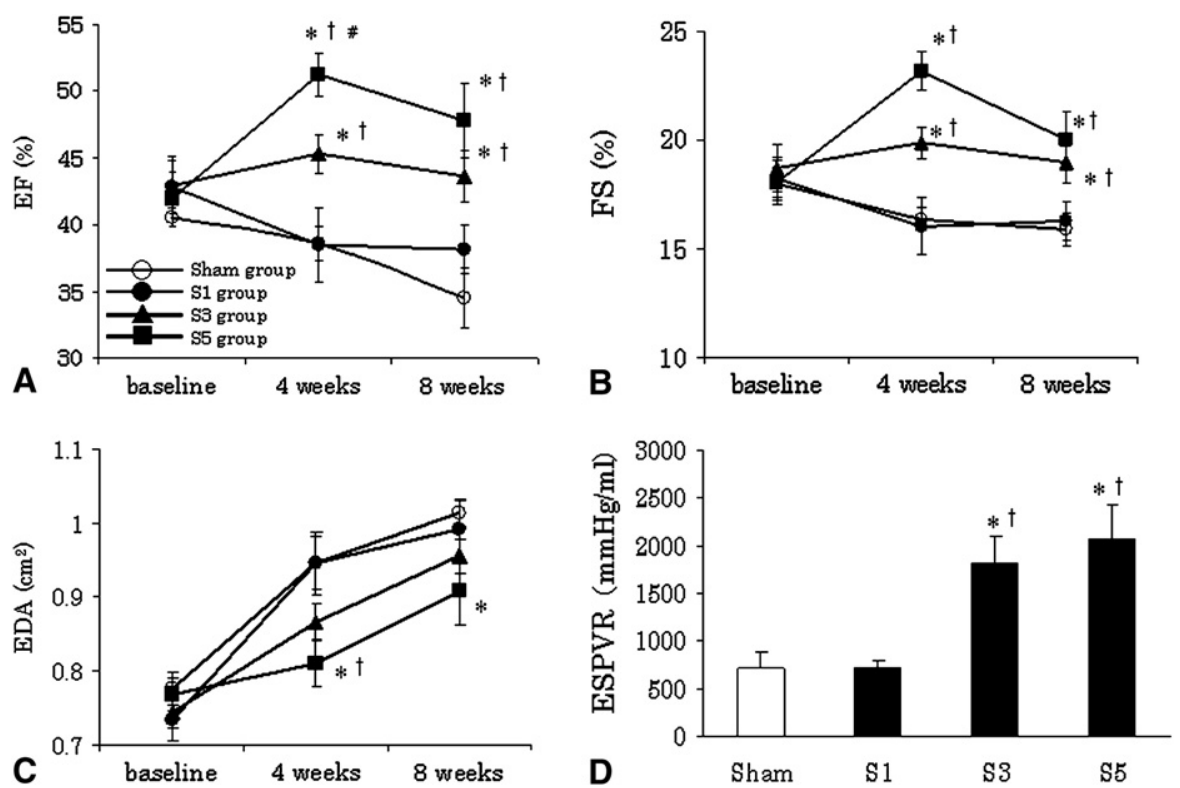

FIGURE 2. Cardiac function after layered myoblast sheet implantation. Echocardiographic measurements of rat heart (A-C). Baseline represents 2 weeks after left anterior descending coronary artery ligation. The pressure-volume study was performed at 8 weeks after treatment to estimate the systolic function of rat heart (D). $* P<.05$ versus sham group. $\dagger P<.05$ versus $\mathrm{S} 1$ group. $\# P<.05$ versus $\mathrm{S} 3$ group. $E F$, Ejection fraction; $F S$, fractional shortening; EDA, enddiastolic area; ESPVR, end-systolic pressure-volume relationship.

least three layers improved systolic function of the impaired heart, although only implantation of five-layered sheets attenuated enlargement of the left ventricle after infarction.

\section{Histologic Improvement of Host Heart After Myoblast Sheet Implantation}

Anterior wall thickness increased in a dose-dependent fashion. Three- and five-sheet implantations significantly thickened the infarcted wall compared with other conditions $(P<.05)$ (Figure $3, A$ to $D$, and Figure $4, A)$. In the infarcted region 4 weeks after implantation, vascular density was significantly higher in the S3 and S5 groups than in the S1 and sham groups $(P<.05)$. There was no significant difference in density between the $\mathrm{S} 3$ and $\mathrm{S} 5$ groups (Figure 3, $E$ to $H$, and Figure $4, B$ ). In noninfarcted regions at 4 weeks, picrosirius red staining revealed significant reduction of fibrosis in the S3 and S5 groups compared with the S1 and sham groups. The fibrosis in the S5 group was significantly reduced compared with that in the $\mathrm{S} 3$ group (Figure 3, I to $L$, and Figure 4, $C$ ). The mean diameters of the myocytes in the S3 and S5 groups were smaller than those in the $\mathrm{S} 1$ and sham groups $(P<.05)$ (Figure 3, $M$ to $P$, and Figure 4, $D$ ).

\section{Assessment of Growth Factors by Gene Expression}

RT-PCR analysis 4 weeks after implantation revealed significantly higher expression of stromal-derived factor 1 (SDF-1) in the S5 group than in the other groups $(P<$ $.05)$. Although expression of vascular endothelial growth factor (VEGF) increased in each group in a dose-dependent fashion, there were no significant differences among groups.
The hepatocyte growth factor (HGF) gene was expressed to significantly higher levels in the S1, S3, and S5 groups than in the sham group (Figure 5). Thus, the hearts implanted with myoblast sheets expressed angiogenetic factors in a dosedependent fashion, and increasing the number of myoblast sheets yielded greater expression of growth factors.

\section{Increase in Elastic Fibers in Implanted Area With Expression of Tropoelastin mRNA}

Masson's elastica staining showed that elastic fibers had increased not only in the implanted sheet layers but also in the infarcted scar area. In the S5 and S3 groups, the implanted sheets including elastic fibers surrounded the host heart over the infarcted area (Figure 6, $A$ to $D$ ). In contrast, they were scarce in the $\mathrm{S} 1$ and sham groups (Figure 6, $E$ and $F$ ). The relative expression of rat tropoelastin mRNA increased in a dose-dependent fashion. Expression in the S5 group was significantly higher than those in the sham and S1 groups $(P<.05)$ (Figure $6, G)$.

\section{DISCUSSION}

In this study, we examined whether increasing the number of cell sheets used to attenuate cardiac remodeling and repair an infarcted myocardial wall improved cardiac performance. We found that implantation of five-layered myoblast sheets yielded favorable results, with improvement of cardiac function, induction of angiogenesis, less fibrosis, and less hypertrophy than the single-layered sheets used in this study or the two-layered sheets used in previous studies. ${ }^{10,11}$ Sheetshaped tissue maintains intact membrane and adhesive 
Sham
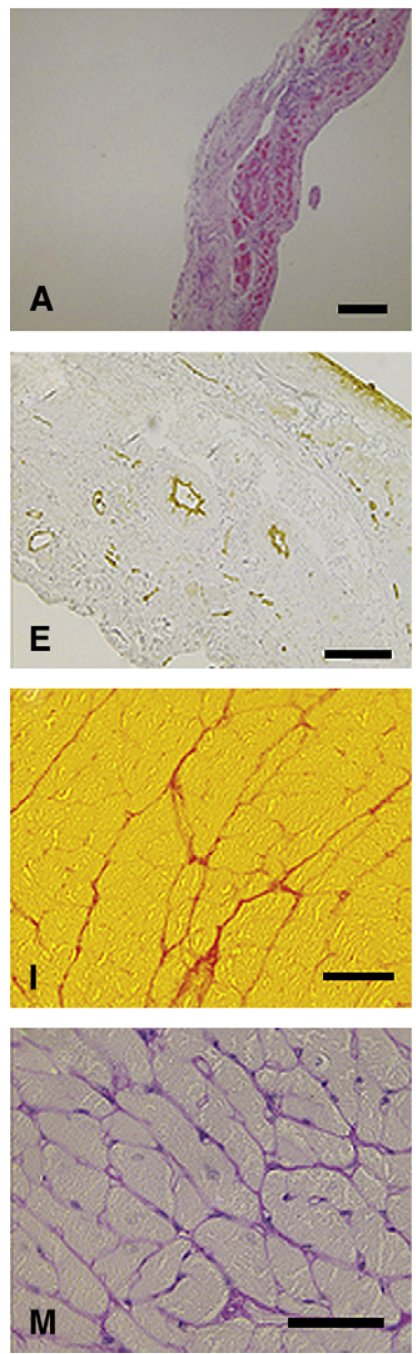

S1
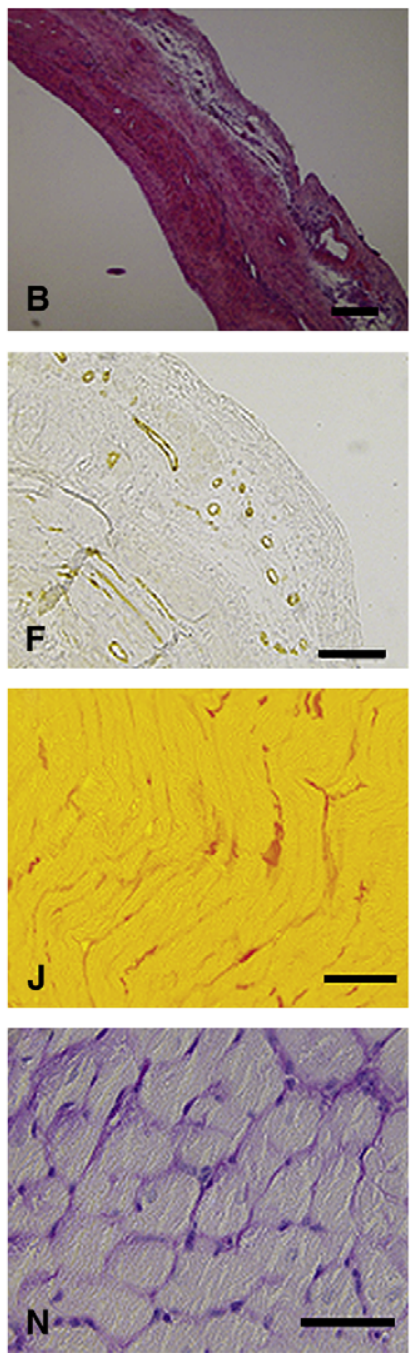

S3
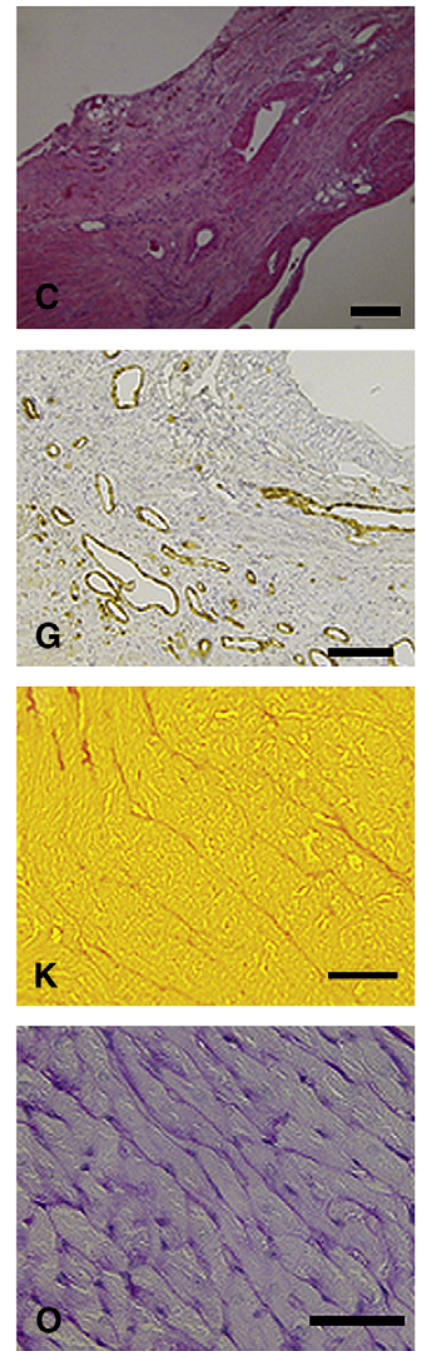

S5
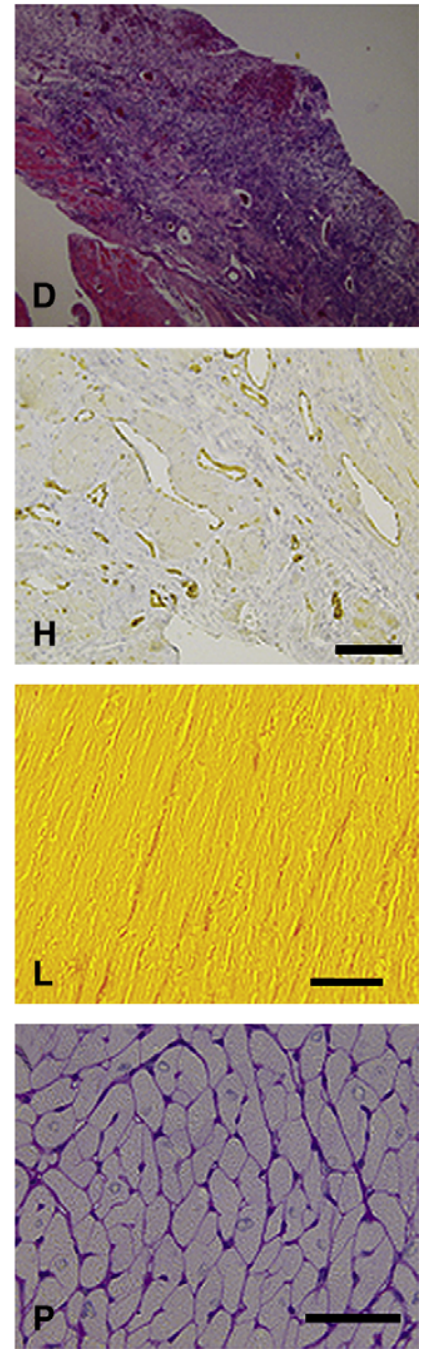

FIGURE 3. Histologic findings of implanted host hearts. Macroscopic $(\times 20)$ view of anterior wall of hearts (hematoxylin and eosin stain): sham, A; S1, B; S3, C; S5, D $($ bar $=200 \mu \mathrm{m})$. Sections of infarcted regions were stained with antibody to von Willebrand factor (factor VIII): sham, E; S11 F; S3, G; S5, H $($ bar $=100 \mu \mathrm{m})$. Sirius-red staining of myocardium of noninfarcted regions: sham, I; S1, J; S3, K; S5, L (bar = $100 \mu \mathrm{m})$. Periodic acid-Schiff-stained myocardium of noninfarcted regions: sham, M; S1, N; S3, O; S5, P $($ bar $=50 \mu \mathrm{m})$.

proteins, incorporates extracellular matrix molecules, secretes growth factors owing to favorable cell-to-cell crosstalk, and prevents cellular microenvironment disruption by enzymatic reactions typically used to detach cells from tissue culture dishes (eg, trypsin or dispase). ${ }^{19}$ These new tissue-engineered cell sheets are expected to be useful for cell delivery to the heart. ${ }^{6,1,12}$

Cardiac remodeling after MI appears to be compensatory initially, but has generally adverse effects and is linked to the progression of heart failure. Cardiomyocyte hypertrophy and interstitial fibrosis are usually observed in the remodeled heart, and greater ventricular enlargement correlates with a poorer prognosis for patients with coronary artery disease. $^{20,21}$ It is, therefore, now widely believed that ventricular remodeling is an important therapeutic target in patients with MI. Here, we treated MI hearts by implantation of layered myoblast sheets and observed decreased remodeling. The mechanism of this attenuation of remodeling may involve efficient delivery of myoblast sheets that overlap the scar area and its borders in the form of a cellular bridge. ${ }^{11}$

Expression of HGF, VEGF, and SDF-1 increases in the host heart implanted with myoblast sheets. ${ }^{11}$ Therefore, layered myoblast sheets may be good suppliers of these factors for impaired hearts. HGF prevents the ventricular remodeling of hearts with established experimental MI. ${ }^{22-25}$ Our previous findings suggested that SDF-1 is released from myoblasts, recruits hematopoietic stem cells, and facilitates repair of the infarcted heart. Similarly, the increased release of HGF and VEGF in the S3 and S5 treatment groups of the current study might have had advantageous effects in 


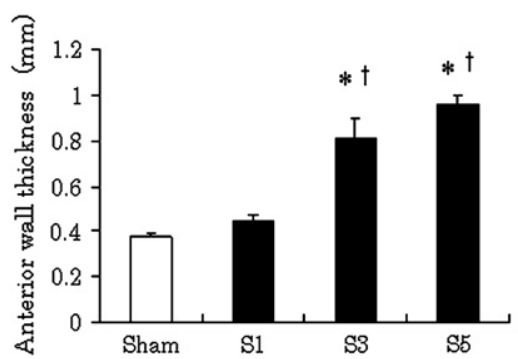

A

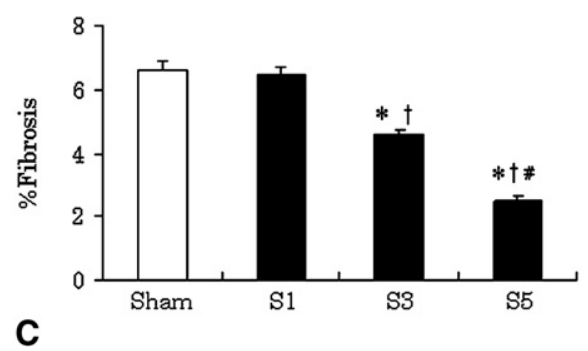

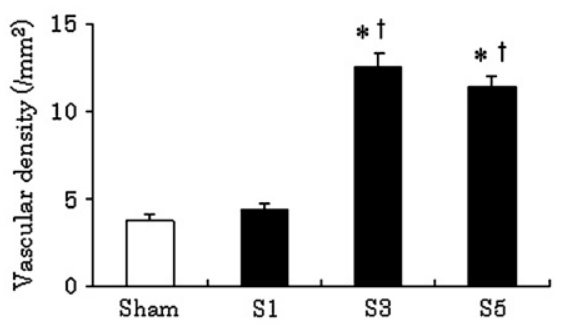

B



FIGURE 4. Quantitative assessment of histologic findings. A, Assessment of anterior wall thickness after implantation. B, Assessment of vascular density in the infarcted area of host hearts vascular density. C, Quantitative results for fibrotic change in the left ventricle. D, Cardiomyocyte short-axis diameters were measured as described in Methods ( $\mathrm{n}=5$ for each group: $\mathrm{A}-\mathrm{D}, 10$ randomly chosen fields per section: $\mathrm{B}-\mathrm{D})$ ). $* P<.05$ versus sham group. $\dagger P<.05$ versus $\mathrm{S} 1$ group. \#P<. 05 versus S3 group.

the damaged heart. On histologic examination, microvessels were increased in the infarcted areas implanted with myoblast sheets. This increased angiogenesis, likely caused by increased HGF, VEGF, and SDF-1, may have improved the microenvironment of the myocytes, rescuing them from cell death or scar formation.

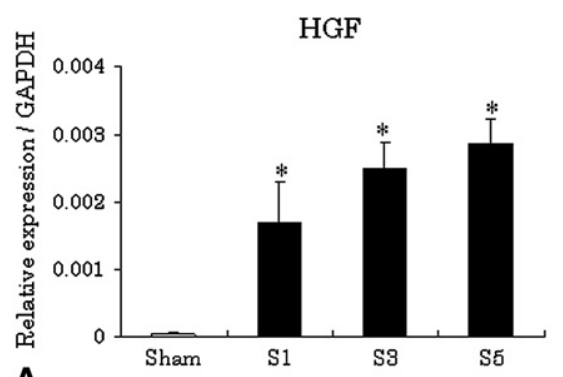

A

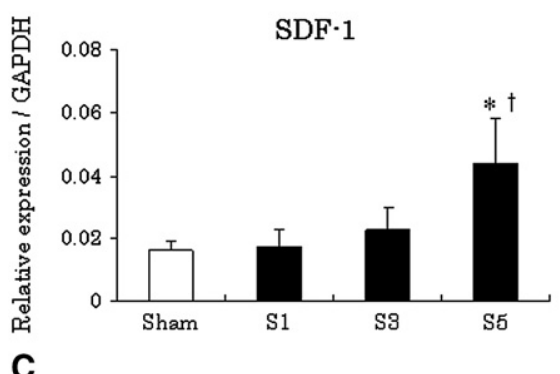

Elastin is a major insoluble extracellular matrix component. The elastic fiber network provides tissue with the critical properties of elasticity and resilient recoil and maintains the integrity of tissue architecture against repeated expansion. ${ }^{26,27}$ Mizuno and colleagues ${ }^{28}$ reported that transplantation of elastin gene-transfected cells attenuated adverse



B

FIGURE 5. Relative expression of growth factors (A-C). Relative levels of mRNA transcripts were measured by the real-time quantitative RT-PCR ( $n=10$ for each of the four groups, S1, S3, S5, and sham). The average copy number of gene transcripts in each sample was normalized to that for glyceraldehyde-3phosphate dehydrogenase $(G A P D H) . * P<.05$ versus sham group. $\dagger P<.05$ versus $\mathrm{S} 1$ group. $H G F$, Hepatocyte growth factor; $V E G F$, vascular endothelial growth factor; $S D F-1$, stromal-derived factor-1. 

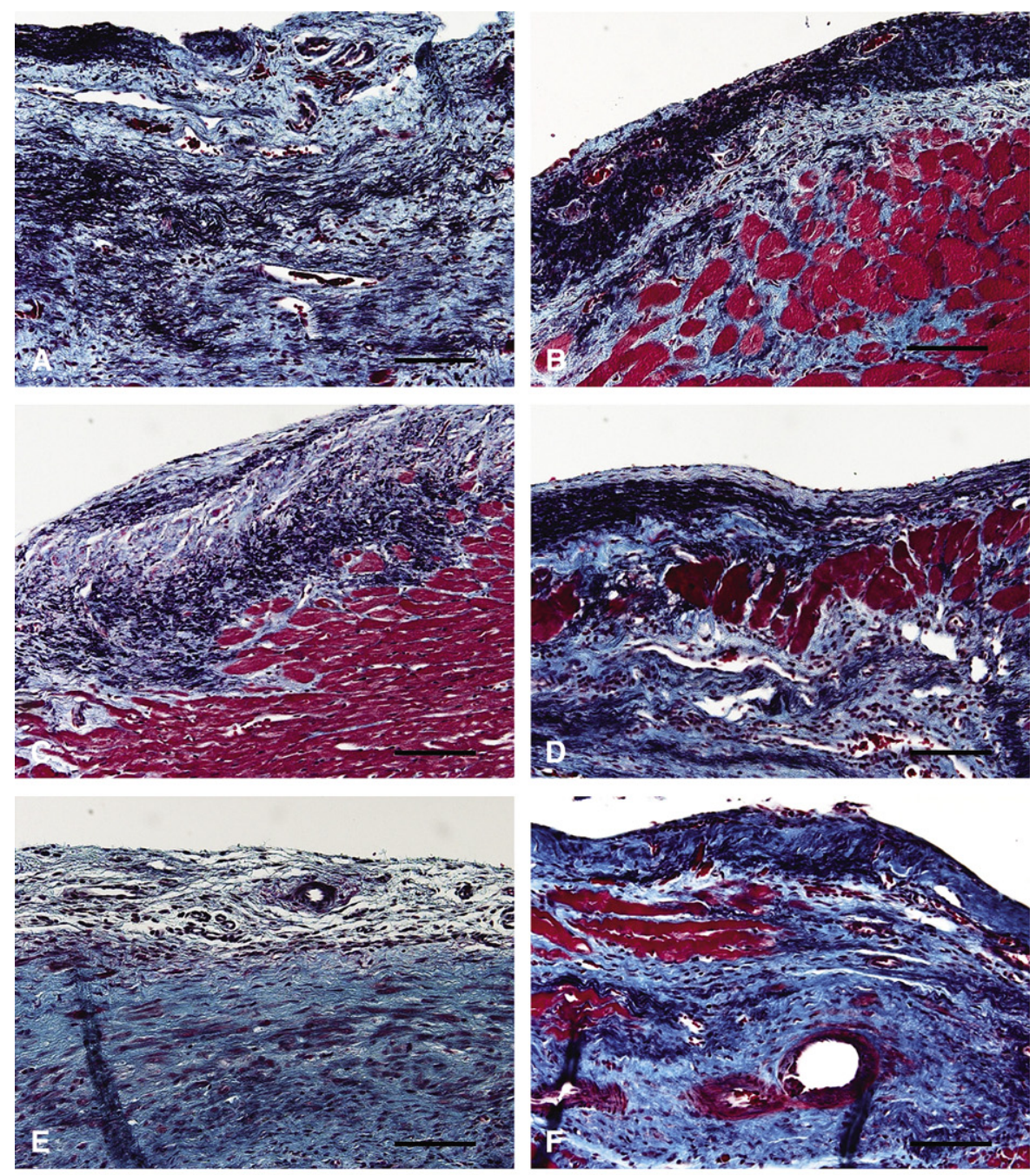

Tropoelastin



FIGURE 6. Elastic fibers were constructed after implantation, with expression of mRNA. Elastic fibers were increased in sheets and host infarcted area in the S5 and S3 groups (S5, A and B; S3, C and D). There were few elastic fibers in the S1 and sham groups (S1, E; sham, F). Relative expression of mRNA of tropoelastin $(\mathrm{G}) . * P<.05$ versus sham group. $\dagger P<.05$ versus $\mathrm{S} 1$ group.

cardiac remodeling of the infarcted heart. The underlying mechanism may involve the addition of elasticity to the infarcted area, permitting recoil in response to the stresses of contraction, which might reduce scar thinning and dilatation. In our studies, implanted myoblast sheets organized elastic fibers not only in the sheet cells but also in the infarcted area of the host heart. Layered myoblast sheet cells might or- ganize the elastic fibers within the cell sheets and infarcted area via expression of tropoelastin, which was expressed more strongly in the layered implantation groups (S3 and S5). It may thus provide elasticity to the host heart, with the improvement of systolic function and less LV dilatation.

We have never detected procedure-induced arrhythmia in these animal models. ${ }^{11-13}$ Menasché and associates ${ }^{6}$ reported 
that sustained ventricular tachycardia might be an adverse effect after myoblast injection. The implantation of myoblast sheets seems to be safe in this regard. We speculate that myoblasts implanted into the heart may have the potential to cause random electrical activity, causing lethal arrhythmia. On the other hand, myoblast sheets implanted outside the epicardium may not generate sufficient aberrant electrical activity to cause lethal arrhythmia. Of course, this is speculation and further investigation, including electrophysiologic studies, is needed.

One of the limitations of this study is that implantation of more than five layers of myoblast sheets was not investigated. However, we tested ten-layered-sheet implantation in this model and found that the LVEF in this group improved to the same level as seen in the S5 group 4 and 8 weeks after implantation (Sekiya and Sawa; unpublished results). This suggests that improvement of cardiac function may plateau at five layers because of the insufficient supply of oxygen and nutrition for myoblasts. This contrasts with the study of Shimizu and associates, ${ }^{14}$ who found that a maximum of three layers could be implanted at one time using cardiomyocyte sheets. Therefore, myoblasts may have a higher tolerance against ischemia and/or hypoxia than cardiomyocytes, and five-layered sheets could be more optimal than threelayered sheets when myoblast sheets are implanted.

Another limitation is of the current study is that the fate of the implanted cells was not tracked. We have begun addressing this by examining sheet cell survival 4 weeks after implantation. In brief, we transplanted male-derived cell sheets onto 15 female infarct hearts that were divided into three groups (S1, one sheet; S3, three sheets; S5, five sheets; $\mathrm{n}=5$ in each group). Four weeks later, genomic DNA was purified from the whole heart, and the male-specific SRY gene, which represented the implanted cells and their derivatives, was measured by real-time quantitative PCR. ${ }^{29}$ The expression ratio of SRY to interleukin 2 gene was as follows $(\%): \mathrm{S} 1(0.05 \pm 0.01)<\mathrm{S} 3(0.22 \pm 0.10, P<.05$ vs S1 $)<$ $\mathrm{S} 5(0.86 \pm 0.16, P<.05$ vs $\mathrm{S} 1, \mathrm{~S} 3)(\mathrm{n}=5$, each group $)$ (Sekiya and Sawa; unpublished results). From these results, we found that more cells survived on the host heart 4 weeks after implantation when a greater number of sheets were implanted. This fact could not directly assess the sheet cell survival on male donor rats. However, we believe that layered sheet implantation yields dose-dependent cell survival after implantation. Although we do not yet know the phenotype of these implanted cells, the survival data were compatible with the dose-dependent growth factor expression and increased wall thickness seen in the experiments presented here.

We propose the following mechanism of repair of the infarcted heart by layered myoblast sheets. At first, the implanted sheets might provide angiogenic and cardioprotective factors, such as HGF, VEGF, and SDF-1, to the host heart. These factors induce angiogenesis in the infarcted area. Additionally, the myoblast sheets mechanically cover the infarcted area and increase its thickness. Then, the implanted sheet cells express the elastin gene and form elastic fibers both in the sheets and in the host heart. The repaired heart, in turn, exhibits reduced wall stress, and LV dilatation, fibrosis, and hypertrophy are prevented.

Recently, we ${ }^{30}$ have investigated 3-dimensional cell sheet construction in vitro using combinations of several different kinds of cells, such as endothelial cells and fibroblasts, aiming to induce vasculogenesis in cell sheets. In the future, beating cell sheets differentiated from pleuripotent stem cells, expressing connexin 43, and containing endothelial cells might be applied to the impaired heart and yield even greater improvement of cardiac function via different mechanisms, such as direct mechanical support through gap junctions, than those reported here.

In summary, our study demonstrated that implantation of myoblast sheets with five layers significantly improved LV systolic function for at least 2 months. Although the mechanism of this effect is not yet clear, a paracrine activity might induce angiogenesis and reduce fibrosis and hypertrophy. Elastic fibers in the cell sheets or host heart might mechanically improve the function of the infarcted heart. Thus, layered myoblast sheets, in optimal numbers, may improve cardiac function and attenuate adverse cardiac remodeling in the infarcted heart. A clinical trial is desired in the near future.

We thank Mrs Masako Yokoyama and Mr Kazuhiro Takekita for their excellent technical assistance and Dr Shannon L. Wyszomierski for correcting the grammar in the manuscript.

\section{References}

1. Taylor DA, Atkins BZ, Hungspreugs P, Jone TR, Reedy MC, Hutcheson KA, et al. Regenerating functional myocardium: improved performance after skeletal myoblast transplantation. Nat Med. 1998;4:929-33.

2. Chachques JC, Acar C, Herreros J, Trainini JC, Prosper F, D'Attellis N, et al. Cellular cardiomyoplasty: clinical application. Ann Thorac Surg. 2004;77:1121-3.

3. Menasché P, Hagege AA, Scorsin M, Puzet B, Desnos B, Schwartz K, et al. Myoblast transplantation in heart failure. Lancet. 2001;357:279-80.

4. Hagege AA, Marolleau JP, Vilqiun JT, Alheritiere A, Peyrard S, Duboc D, et al. Skeletal myoblast transplantation in ischemic heart failure: long-term follow-up of the first phase I cohort of patients. Circulation. 2006;114:I108-13.

5. Dib N, Michler RE, Pagani FD, Wright S, Kereiakes DJ, Lengerich R, et al. Safety and feasibility of autologous myoblast transplantation in patients with ischemic cardiomyopathy: four-year follow-up. Circulation. 2005;112:1748-55.

6. Menasché P, Hagege AA, Vilquin JT, Desnos M, Abergel E, Pouzet B, et al. Autologous skeletal myoblast transplantation for severe postinfarction left ventricular dysfunction. J Am Coll Cardiol. 2003;41:1078-83.

7. Pagani FD, DerSimonian H, Zawadzka A, Wetzel K, Edge AS, Jacoby DB, et al. Autologous skeletal myoblasts transplanted to ischemia-damaged myocardium in humans. Histological analysis of cell survival and differentiation. J Am Coll Cardiol. 2003;41:1078-83.

8. Suzuki K, Murtuza B, Fukushima S, Smolenski RT, Varela-Carver A, Coppen SR, et al. Targeted cell delivery into infarcted rat hearts by retrograde intracoronary infusion: distribution, dynamics, and influence on cardiac function. Circulation. 2004;110(Suppl II):II-225-30.

9. Okano T, Yamada N, Okuhara M, Sakai H, Sakurai Y. Mechanism of cell detachment from temperature-modulated, hydrophilic-hydrophobic polymer surfaces. Biomaterials. 1995; 16:297-303.

10. Miyagawa S, Sawa Y, Kitagawa-Sakakida S, Taketani S, Kondoh H, Memon IA, et al. Tissue cardiomyoplasty using bioengineered contractile cardiomyocyte sheets to repair damaged myocardium: their integration with recipient myocardium. Transplantation. 2005;80:1586-95. 
11. Memon IA, Sawa Y, Fukushima N, Matsumiya G, Miyagawa S, Taketani S, et al. Repair of impaired myocardium by means of implantation of engineered autologous myoblasts sheets. J Thorac Cardiovasc Surg. 2005;130:1333-41.

12. Kondoh H, Sawa Y, Miyagawa S, Sakakida-Kitagawa S, Memon IA, Kawaguchi N, et al. Longer preservation of cardiac performance by sheet-shaped myoblast implantation in dilated cardiomyopathy hamsters. Cardiovasc Res. 2005;69:466-75.

13. Hata H, Matsumiya G, Miyagawa S, Kondoh H, Kawaguchi N, Matsuura N, et al. Grafted skeletal myoblast sheets attenuate myocardial remodeling in pacing-induced canine heart failure model. J Thorac Cardiovasc Surg. 2006;132: 918-24.

14. Shimizu T, Sekine H, Yang J, Isoi Y, Yamato M, Kikuchi A, et al. Polysurgery of cell sheet grafts overcomes diffusion limits to produce thick, vascularized myocardial tissues. FASEB J. 2006;20:708-10.

15. Wiesman HF, Bush DE, Mannisi JA, Weisfeldt ML, Healy B. Cellular mechanism of myocardial infarct expansion. Circulation. 1988;78:186-201.

16. Nishio R, Sasayama S, Matsumori A. Left ventricular pressure-volume relationship in a murine model of congestive heart failure due to acute viral myocarditis. $J$ Am Coll Cardiol. 2002;40:1506-14.

17. Lekgave ED, Kiriazis H, Zhao C, Xu Q, Moore XL, Su Y, et al. Relaxin reverses cardiac and renal fibrosis in spontaneously hypertensive rats. Hypertension. 2005; 46:412-8.

18. Horiguchi K, Sakakida-Kitagawa S, Sawa Y, Li ZZ, Fukushima N, Shirakura R, et al. Selective chemokine and receptor gene expressions in allografts that develop transplant vasculopathy. J Heart Lung Trasnplant. 2002;21: 1090-100.

19. Kushida A, Yamato M, Okano T, Kikuchi A, Sakurai Y, Okano T. Decrease in culture temperature releases monolayer endothelial cell sheets together with deposited fibronectin matrix from temperature-responsive culture surfaces. $J \mathrm{Bi}$ omed Mater Res. 1999;45:355-62.
20. Sharpe N. Cardiac remodeling in coronary artery disease. Am J Cardiol. 2003 93(suppl):17B-20B.

21. Opie LH, Commerford PJ, Gersh BJ, Pfeffer MA. Controversies in ventricular remodeling. Lancet. 2006;367:356-67.

22. Cittandini A, Grossman BA, Raffaele N, Katz S, Stromer H, Smith RJ, et al. Growth hormone attenuates early left ventricular remodeling and improves cardiac function in rats with large myocardial infarction. J Am Coll Cardiol. 1997;29:1109-16.

23. Li Y, Takemura G, Kosai K, Yuge K, Nagano S, Esaki M, et al. Postinfarction treatment with an adenoviral vector expressing hepatocyte growth factor relieves chronic left ventricular remodeling and dysfunction in mice. Circulation. 2003;107:2499-506.

24. Askari AT, Unzek S, Popovic ZB, Goldman CK, Torudi F, Penn MS, et al. Effect of stromal-cell-derived factor 1 on stem-cell homing and tissue regeneration in ischemic cardiomyopathy. Lancet. 2003;362:697-703.

25. Rarajczak MZ, Majaka M, Kucia M, Drukala J, Piper S, Janowska WA, et al. Expression of functional CXCR4 by muscle satellite cells and secretion of SDF-1 by muscle-derived fibroblasts is associated with the presence of both muscle progenitors in bone marrow and hematopoietic stem/progenitor cells in muscles. Stem Cell. 2003;21:363-71.

26. Kielty CM, Sherratt MJ, Shuttleworth CA. Elastic fibers. J Cell Sci. 2002;115 2817-28.

27. Nakamura T, Lozano PR, Ikeda Y, Iwanaga Y, Hinek A, Minamisawa S, et al. Fibulin-5/DANCE is essential for elastogenesis in vivo. Nature. 2002;415:171-5.

28. Mizuno T, Terrence MY, Richard DW, Chris GK, Li R-K. Elastin stabilizes an infarct and preserves ventricular function. Circulation. 2005;112:I-81-8.

29. Kitagawa-Sakakida S, Tori M, Li Z, Horiguch K, Izutani H, Matsuda H, et al. Active cell migration in retransplanted rat cardiac allograft during the course of chronic rejection. J Heart Lung Transplant. 2000;19:584-90.

30. Tsuda Y, Shimizu T, Yamato M, Kikuchi A, Sasagawa T, Sekiya S, et al. Cellular control of tissue architectures using a three-dimensional tissue fabrication technique. Biomaterials. 2007;28:4939-46. 